\title{
Noninvasive Monitoring of Oxygen and Ventilation
}

\author{
Craig D Smallwood RRT and Brian K Walsh PhD RRT-NPS RRT-ACCS RPFT AE-C FAARC
}

\author{
Introduction \\ Carbon Dioxide Monitoring \\ Gas Exchange Monitoring \\ Near-Infrared Spectroscopy \\ Transcutaneous Carbon Dioxide and Oxygen \\ Pulse Oximetry \\ Electrical Impedance Tomography \\ Summary
}

\begin{abstract}
Noninvasive monitoring of oxygenation and ventilation is an essential part of pediatric respiratory care. Carbon dioxide, gas exchange monitoring, transcutaneous monitoring, near-infrared spectroscopy, pulse oximetry, and electrical impedance tomography are examined. Although some of these technologies have been utilized for decades, incorporation into mechanical ventilators and recently developed methods may provide important clinical insights in a broader patient range. Less mature technologies (electrical impedance tomography and near-infrared spectroscopy) have been of particular interest, since they offer easy bedside application and potential for improved care of children with respiratory failure and other disorders. This article provides an overview of the principles of operation, a survey of recent and relevant literature, and important technological limitations and future research directions. [Respir Care 2017;62(6):751-764. (C) 2017 Daedalus Enterprises]
\end{abstract}

\section{Introduction}

Noninvasive monitoring of oxygenation and ventilation is an essential part of pediatric respiratory care. The cen-

The authors are affiliated with the Division of Critical Care Medicine, Department of Anesthesiology, Perioperative and Pain Medicine, Boston Children's Hospital, Boston, Massachusetts and Harvard Medical School, Boston, Massachusetts.

The authors have disclosed relationships with GE Healthcare and Draeger Medical.

Mr Smallwood presented a version of this paper at the 55th RESPIRATORY CARE Journal Conference, "Pediatric Respiratory Care," held June 10-11, 2016, in St Petersburg, Florida.

Correspondence: Craig D Smallwood RRT, Division of Critical Care Medicine, Department of Anesthesiology, Pain and Perioperative Medicine, MSICU Office, Bader 634, Boston Children's Hospital, 300 Longwood Avenue, Boston, MA 02115. E-mail: craig.smallwood@childrens.harvard.edu.

DOI: $10.4187 /$ respcare. 05243 tral purpose of this article is to provide a summary of existing technologies that support the noninvasive monitoring of $\mathrm{CO}_{2}$ and $\mathrm{O}_{2}$. For technologies that have been utilized for decades, technological refinement and development of novel methods may enable application to a broader population. For newer devices, a survey of existing validation and discussion of potential clinical applications are provided. For all technologies, an overview of the underlying principles of operation, limitations, and proposed future directions are discussed.

\section{Carbon Dioxide Monitoring}

Monitoring patency of artificial airways and adequacy of ventilation is an essential component of the care of patients with acute respiratory illness. End-tidal $\mathrm{CO}_{2}$ monitoring $\left(\mathrm{P}_{\mathrm{ETCO}_{2}}\right)$ is a partial pressure measurement of $\mathrm{CO}_{2}$ gas at end exhalation. The measurement is commonly expressed as either a partial pressure $(\mathrm{mm} \mathrm{Hg}, \mathrm{kPa})$ or a fraction (\%). Although often used interchangeably, $\mathrm{P}_{\mathrm{ETCO}_{2}}$ 
monitoring is composed of capnometry and capnography. Capnometry refers to the use of the numeric value of $\mathrm{P}_{\mathrm{ETCO}_{2}}$, and capnography refers to the display and interpretation of $\mathrm{P}_{\mathrm{ETCO}_{2}}$ plotted against time.

\section{Function of Mainstream and Sidestream Capnometry and Capnography}

There are 2 main methods of obtaining $\mathrm{P}_{\mathrm{ETCO}_{2}}$ values: mainstream and sidestream. A mainstream capnometer is one where the non-dispersive infrared sensor used to detect $\mathrm{CO}_{2}$ levels is located at the airway. A sidestream capnometer incorporates an airway adapter, a sample line through which airway gas is continuously aspirated, a water trap and filter assembly to prevent water buildup inside the device, an infrared sensor, and a gas pump. ${ }^{1}$ Advantages of mainstream devices include near-real-time display of graphics and $\mathrm{P}_{\mathrm{ETCO}}$ values; reduced risk of blockage and measurement interruption from the accumulation of water condensate compared with the sidestream, since the adapter is heated; superior accuracy with arterial $\mathrm{CO}_{2}$; and more accurate waveform data in the neonatal and pediatric population. ${ }^{2,3}$ Disadvantages of the mainstream $\mathrm{P}_{\mathrm{ETCO}_{2}}$ sensor include the weight of the device on the airway (which is most relevant in the neonatal population) and difficulty in applying the device noninvasively. On the other hand, sidestream devices offer reduced airway adapter weight, can be readily adapted into a nasal cannula for use in children who do not have an artificial airway, and are conventionally integrated into bedside monitors for rapid deployment during resuscitation and emergent intubation. However, operation of a sidestream device incorporates a delay of several seconds and offers reduced agreement with $\mathrm{P}_{\mathrm{aCO}}$ and inaccurate waveforms. ${ }^{3,4}$ This delay is primarily a function of the sample line volume and aspiration rate; a larger sample line volume and slower aspiration rate would result in a longer delay time. ${ }^{4}$

The time point at which the $\mathrm{P}_{\mathrm{ETCO}}$ value is abstracted from the respiratory cycle can be determined in a number of ways. If the device also measures flow, $\mathrm{P}_{\mathrm{ETCO}_{2}}$ can be obtained at the point just before exhalation transitions to inspiration. If flow is unknown, the device may either: (1) display the value just before the marked decrease in $\mathrm{CO}_{2}$ concentration is observed, (2) display the average value across the entire exhalation, or (3) display the maximum value observed during exhalation. The specific methodology will be manufacturer- and device-dependent.

Important clinical insights can be gleaned by the appropriate interpretation of capnographic waveforms in infants and children. A thorough review of capnographic waveforms is beyond the scope of the present article, and readers are encouraged to see the excellent review by Thompson and Jaffe. ${ }^{5}$

\section{Indications}

Tracheal Intubation. Confirmation of an adequate artificial airway is a chief use of $\mathrm{P}_{\mathrm{ETCO}}$ devices. Use is indicated in neonates, infants, and pediatric patients following intubation and during mechanical ventilation. ${ }^{6-8}$ In addition, colorimetric end-tidal $\mathrm{CO}_{2}$ devices have also been shown to be effective in children in the absence of an electronic device. ${ }^{9}$ Colorimetric $\mathrm{CO}_{2}$ devices utilize a $\mathrm{pH}-$ sensitive chemical indictor that changes color in the presence of $\mathrm{CO}_{2}$ gas. Although colorimetric devices are fairly reliable, they do offer the possibility of a false positive due to a build up of $\mathrm{CO}_{2}$ in the gastric system. For this reason, it is preferred to utilize capnography to confirm airway placement. Use of continuous monitoring is also important during transport of mechanically ventilated children and provides assurance that the artificial airway is in position. ${ }^{10}$

Adequacy of Ventilation and Severity of Illness. Continuous monitoring of $\mathrm{P}_{\mathrm{ETCO}_{2}}$ can be useful to ensure adequate ventilation in both mechanically supported and spontaneously breathing patients. ${ }^{11-13}$ In healthy children, the expected gradient between $\mathrm{P}_{\mathrm{ETCO}_{2}}$ and $\mathrm{P}_{\mathrm{aCO}_{2}}$ is $2-5 \mathrm{~mm} \mathrm{Hg}$. A common misconception is that during critical illness, $\mathrm{P}_{\mathrm{ETCO}_{2}}$ ceases to correlate with $\mathrm{P}_{\mathrm{aCO}}$, particularly in severely ill patients. However, these values always correlate, but changes in the physiologic dead-space affect $\mathrm{P}_{\mathrm{ETCO}_{2}}-$ $\mathrm{P}_{\mathrm{aCO}_{2}}$ and are therefore a reflection of ventilation efficiency and, more broadly, severity of illness. ${ }^{14}$ Physiologic dead-space fraction $\left(\mathrm{V}_{\mathrm{D}} / \mathrm{V}_{\mathrm{T}}\right)$ is an important concept in pediatric critical care medicine because it represents the proportion of tidal volume not involved in gas exchange. A standard method of computing $\mathrm{V}_{\mathrm{D}} / \mathrm{V}_{\mathrm{T}}$ utilizes the Enghoff modification of the Bohr equation.

$$
\mathrm{V}_{\mathrm{D}} / \mathrm{V}_{\mathrm{T}}=\left(\mathrm{P}_{\mathrm{aCO}_{2}}-\mathrm{P}_{\overline{\mathrm{E} C O}}\right) / \mathrm{P}_{\mathrm{aCO}}
$$

Importantly, computation of $\mathrm{V}_{\mathrm{D}} / \mathrm{V}_{\mathrm{T}}$ typically requires a volumetric capnographic device that simultaneously measures $\mathrm{CO}_{2}$ concentrations as well as flow. The volumeaverage exhaled $\mathrm{CO}_{2}$ concentration $\left(\mathrm{P}_{\overline{\mathrm{ECO}}}\right)$ is required for the calculation of $\mathrm{V}_{\mathrm{D}} / \mathrm{V}_{\mathrm{T}}$. Volumetric capnography is outlined in further detail below. $\mathrm{V}_{\mathrm{D}} / \mathrm{V}_{\mathrm{T}}$ has been shown to be associated with severity of lung injury and oxygenation disturbances, prediction of extubation success, and mortality risk. ${ }^{15-18}$ Further, investigations in children have assessed the utility of end-tidal alveolar dead-space fraction. ${ }^{19}$ This method utilizes $\mathrm{P}_{\mathrm{ETCO}_{2}}$ measurements in place of the $\mathrm{P}_{\overline{\mathrm{ECO}}}$. The method was shown to be of strong correlation with the Enghoff-Bohr method in children with mild lung injury but poor correlation in subjects with moderate or severe lung injury. In children with $\mathrm{P}_{\mathrm{OO}_{2}} / \mathrm{F}_{\mathrm{IO}_{2}} \geq 300$, 


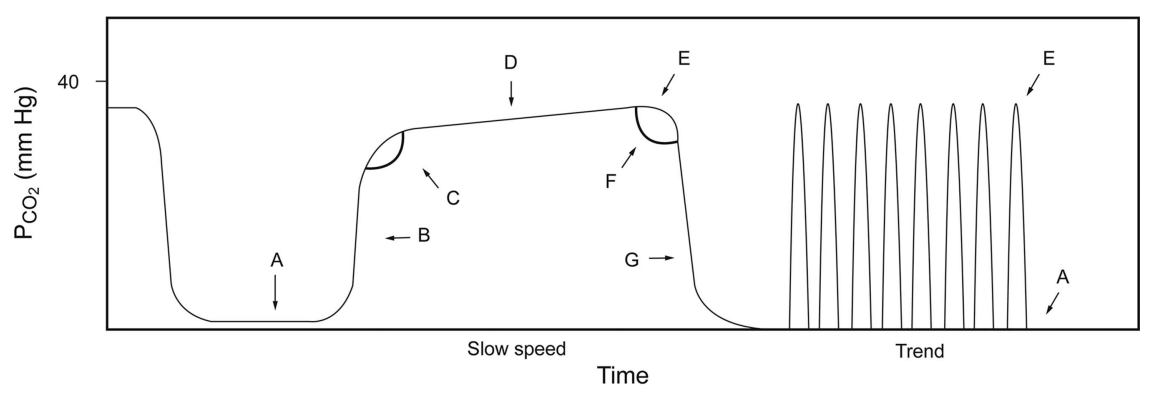

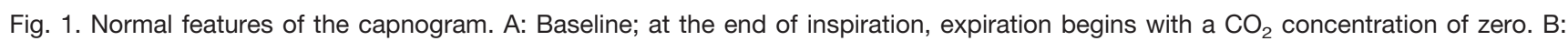
Transitional; a rapid increase in $\mathrm{CO}_{2}$ is observed as the subject exhales, representing mixed alveolar and dead space gas. C: $\alpha$ angle, which represents change from transitional to alveolar gas. D: Alveolar gas; expect this region to be fairly flat, sometimes referred to as the alveolar plateau. E: Point at which end-tidal $\mathrm{CO}_{2}$ is typically measured. $\mathrm{F}: \beta$ angle, change from expiration to inspiration. $\mathrm{G}$ : $\mathrm{A}$ rapid decrease in $\mathrm{CO}_{2}$ concentration is expected and observed as inspiration begins. The right-hand portion of the figure shows a time-compressed version of the same waveform and is useful for trending. From Reference 5.

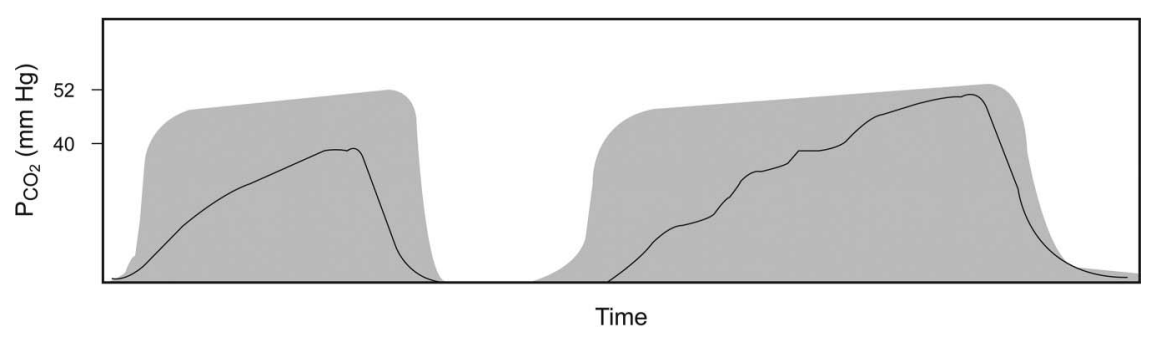

Fig. 2. Obstruction. The rate of rise during the transitional phase of the capnogram is slow, and an alveolar plateau is not readily distinguished. The shaded area is the normal capnogram for reference. From Reference 5.

agreement between Bohr and Enghoff is negligible. ${ }^{20} \mathrm{How}-$ ever, the clinical importance of this finding is less clear, since $\mathrm{V}_{\mathrm{D}} / \mathrm{V}_{\mathrm{T}}$ is primarily of interest in children with lung injury who typically have $\mathrm{P}_{\mathrm{aO}} / \mathrm{F}_{\mathrm{IO}_{2}} \leq 300$. More work is required in this area, since it is clinically desirable to have a bedside assessment of $\mathrm{V}_{\mathrm{D}} / \mathrm{V}_{\mathrm{T}}$, and many clinicians may not have access to volumetric capnography.

Another important application of $\mathrm{P}_{\mathrm{ETCO}_{2}}$ is in the nonintubated child receiving or recovering from anesthesia. Since hypoventilation and apnea are common in children, capnography may improve recognition of respiratory depression and improve safety. ${ }^{12,21}$ Importantly, the nasal cannula interface may not be tolerated in all subjects, and care should be taken to ensure proper cannula placement and device function. ${ }^{22} \mathrm{~A}$ recent randomized controlled trial assessing the affect of capnography during postanesthesia care demonstrated different rates of adverse respiratory events overtime in children undergoing capnography compared with only pulse oximetry. ${ }^{23}$ Capnography appeared to improve the efficacy of staff interventions but did not have a significant effect on oxygen desaturation events.

Cardiopulmonary Resuscitation. In addition to confirmation of an advanced airway discussed previously, the utility of $\mathrm{P}_{\mathrm{ETCO}}$ has been noted during cardiopulmonary resuscitation. Current data indicate that a $\mathrm{P}_{\mathrm{ETCO}_{2}}$ target of $>10 \mathrm{~mm} \mathrm{Hg}$ is associated with the return of sponta- neous circulation and can be useful in deciding when to terminate cardiopulmonary resuscitation. ${ }^{24,25} \mathrm{P}_{\mathrm{ETCO}_{2}}$ monitoring is an effective metric to assess the quality of external chest compressions, where higher values are associated with improved survival rates ${ }^{26}$ as well as being a gross marker of return of spontaneous circulation. ${ }^{27}$

Waveform Interpretation. The capnogram has several features that permit clinical interpretation. ${ }^{5}$ The best thing a clinician can do is to thoroughly understand each portion of the normal capnogram. Abnormalities observed in individual subjects can then be interpreted relative to the expected characteristics. The normal pediatric waveform is depicted in Figure 1. Although many distinct pathophysiologic phenomena can be detected on the capnogram, 4 important ones are outlined below that are often observed in the pediatric population: airway obstruction (Fig. 2), patient effort/asynchrony (Fig. 3), $\mathrm{CO}_{2}$ rebreathing (Fig. 4), and bronchial intubation (Fig. 5).

\section{Limitations and Future Directions of Investigation}

Interpretations of capnography waveforms should be done complementary to the clinical picture. Findings can either: (1) serve as an early warning sign of a pathophysiologic process or (2) provide corroborative evidence (eg, a clinician may 


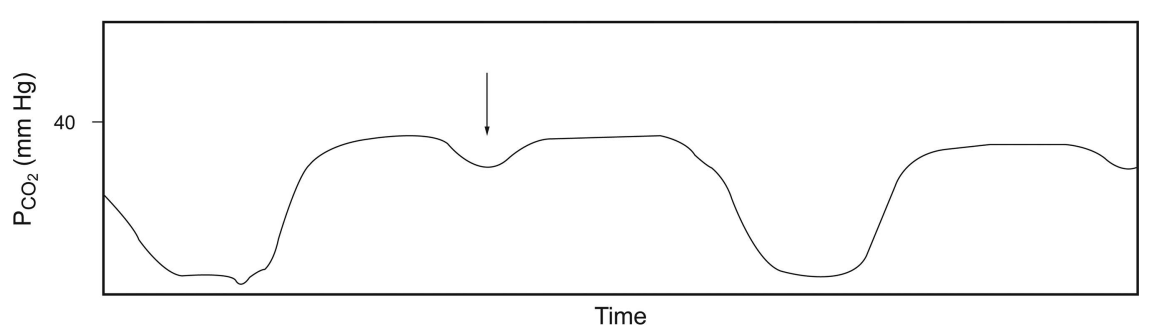

Fig. 3. Patient effort. The arrow points to a portion of the capnogram during which a slight dip in $\mathrm{CO}_{2}$ concentration is observed. This can be indicative of a patient effort during mechanical ventilation that did not trigger a breath. From Reference 5.

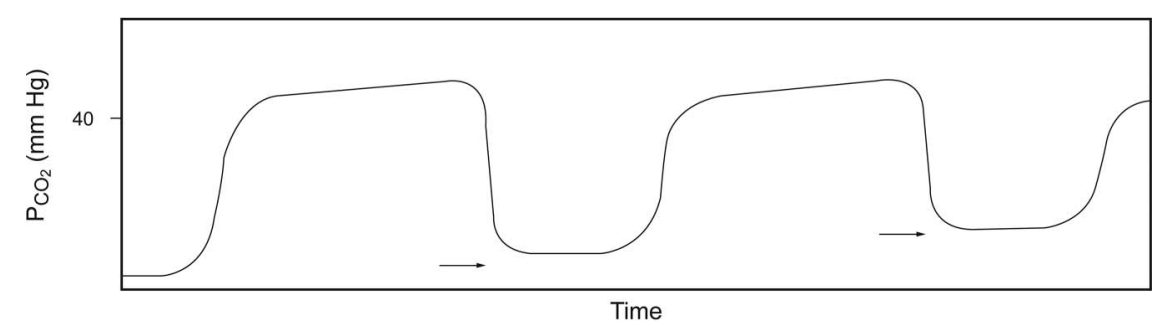

Fig. 4. $\mathrm{CO}_{2}$ rebreathing. The baseline is seen above a level of zero (arrows) and increasing in this case. This can result from inadequate time for inspiration or excessive mechanical dead space. From Reference 5.

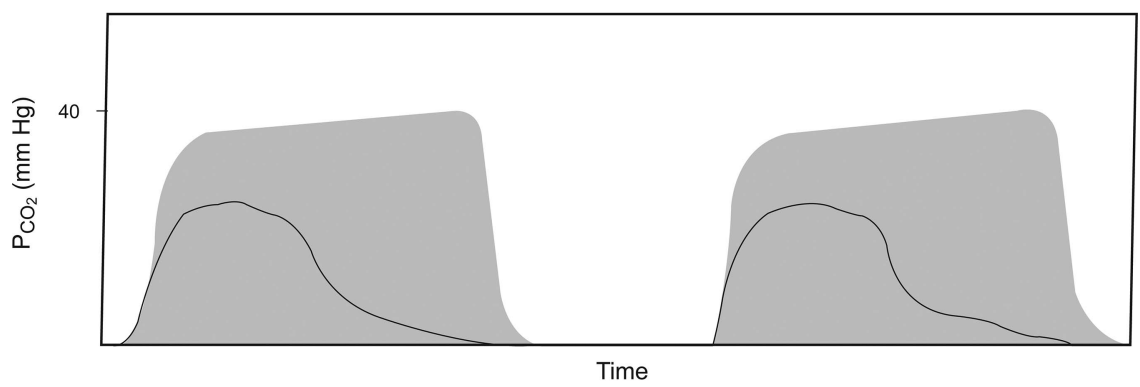

Fig. 5. Intubation of bronchus. An acute change from a normal capnogram (shaded area). The endotracheal tube migrated down the right or left main bronchus. This is an important consideration in children, since the tolerance of appropriate endotracheal insertion depth is relatively small. From Reference 5 .

suspect an acute worsening in obstruction by auscultation and then confirm this by inspecting the capnograph).

Future directions include automated waveform interpretation and alerting, as has been demonstrated by Kazemi et al, ${ }^{28}$ who devised a method to automatically detect the severity of obstruction during asthma from capnographic information. Importantly, collaborations between respiratory clinicians, engineers, and data scientists should be fostered to improve the clinical utility of capnometry and capnography and to enhance decision support at the bedside.

\section{Gas Exchange Monitoring}

Gas exchange monitoring comprises the application of a device to measure the flow (volume per unit time, into and out of the body) and partial pressure of the 2 main gases involved in human respiration: oxygen and carbon dioxide. These data are integrated to extract the volume of respiratory gases being consumed and extreted by the body. Aerobic metabolism is the primary process by which humans combust nutrients to obtain energy. The process consumes $\mathrm{O}_{2}$ and produces $\mathrm{CO}_{2}$, which is transported by the blood and excreted by the respiratory system. Oxygen consumption $\left(\dot{\mathrm{V}}_{\mathrm{O}_{2}}\right)$ refers to the volume of oxygen consumed per unit time (typically expressed in $\mathrm{mL} / \mathrm{min}$ ), and carbon dioxide elimination $\left(\dot{\mathrm{V}}_{\mathrm{CO}_{2}}\right)$ refers to the volume of $\mathrm{CO}_{2}$ eliminated per unit time (typically expressed in $\mathrm{mL} / \mathrm{min}$ ).

\section{Function}

There are various devices available on the market to measure $\dot{\mathrm{V}}_{\mathrm{O}_{2}}$ and $\dot{\mathrm{V}}_{\mathrm{CO}_{2}}$. These devices incorporate either an oxygen sensor (typically a paramagnetic or galvanic cell) to measure the concentration of $\mathrm{O}_{2}$ or a $\mathrm{CO}_{2}$ sensor (typically a non-dispersive infrared sensor) to measure the concentration of $\mathrm{CO}_{2}$ and a pneumotachometer to measure 
Table 1. Specifications of Gas Exchange Monitors Available in Mechanical Ventilators

\begin{tabular}{|c|c|c|c|c|c|c|}
\hline Device and Manufacturer & $\begin{array}{l}\text { Carbon Dioxide } \\
\text { Sensor Type } \\
\text { (Sampling) }\end{array}$ & $\begin{array}{l}\mathrm{CO}_{2} \text { Specification } \\
\text { Range (Accuracy) }\end{array}$ & $\begin{array}{l}\text { Oxygen } \\
\text { Sensor }\end{array}$ & $\begin{array}{c}\mathrm{O}_{2} \text { Specification } \\
\text { Range (Accuracy) }\end{array}$ & $\dot{\mathrm{V}}_{\mathrm{CO}_{2}} \begin{array}{l}\text { Accuracy Range } \\
\text { (Accuracy) }\end{array}$ & $\dot{\mathrm{V}}_{\mathrm{O}_{2}} \begin{array}{l}\text { Accuracy Range } \\
\text { (Accuracy) }\end{array}$ \\
\hline $\begin{array}{l}\text { Avea (Carefusion, San } \\
\text { Diego, California) }\end{array}$ & NDIR (mainstream) & $\begin{array}{c}0-150 \mathrm{~mm} \mathrm{Hg} \\
( \pm 2 \mathrm{~mm} \mathrm{Hg} \text { for } \\
0-40 \mathrm{~mm} \mathrm{Hg})^{*}\end{array}$ & $\mathrm{NA} \dagger$ & $\mathrm{NA} \dagger$ & Not specified & $\mathrm{NA} \dagger$ \\
\hline $\begin{array}{l}\text { V500 (Dräger, Lübeck, } \\
\text { Germany) }\end{array}$ & Not specified & $\begin{array}{c}0-100 \mathrm{~mm} \mathrm{Hg} \\
( \pm 2 \mathrm{~mm} \mathrm{Hg} \text { for } \\
0-40 \mathrm{~mm} \mathrm{Hg}) \ddagger\end{array}$ & $\mathrm{NA} \dagger$ & $\mathrm{NA} \dagger$ & 0-999 mL/min $( \pm 12 \%)$ & $\mathrm{NA} \dagger$ \\
\hline $\begin{array}{l}\text { R860 (GE Healthcare, } \\
\text { Madison, Wisconsin) }\end{array}$ & NDIR (sidestream) & $\begin{array}{l}0-15 \%( \pm 0.2 \%+ \\
2 \% \text { of reading })\end{array}$ & Paramagnetic & $\begin{array}{l}0-100 \%( \pm 1 \%+2 \% \\
\text { of reading) }\end{array}$ & $\begin{array}{l}20-1,000 \mathrm{~L} / \mathrm{min}( \pm 10 \% \\
\text { or } 10 \mathrm{~mL} \text { for } \\
\left.\mathrm{O}_{2}<65 \%\right) \S\end{array}$ & $\begin{array}{l}20-1,000 \mathrm{~L} / \mathrm{min} \\
\quad( \pm 10 \% \text { or } 10 \mathrm{~mL} \\
\left.\quad \text { for } \mathrm{O}_{2}<65 \%\right) \S\end{array}$ \\
\hline $\begin{array}{l}\text { G5 (Hamilton Medical, } \\
\text { Bonaduz, Switzerland) }\end{array}$ & NDIR (mainstream) & $\begin{array}{l}0-150 \mathrm{~mm} \mathrm{Hg} \\
( \pm 2 \mathrm{~mm} \mathrm{Hg} \text { for } \\
0-40 \mathrm{~mm} \mathrm{Hg})^{*}\end{array}$ & $\mathrm{NA} \dagger$ & $\mathrm{NA} \dagger$ & $0-5,000 \mathrm{~mL} / \mathrm{min}$ & $\mathrm{NA} \dagger$ \\
\hline $\begin{array}{l}\text { Servo-i (Maquet, Wayne, } \\
\text { New Jersey) }\end{array}$ & NDIR (mainstream) & $\begin{array}{l}0-150 \mathrm{~mm} \mathrm{Hg} \\
( \pm 2 \mathrm{~mm} \mathrm{Hg} \text { for } \\
0-40 \mathrm{~mm} \mathrm{Hg})^{*}\end{array}$ & $\mathrm{NA} \dagger$ & $\mathrm{NA} \dagger$ & Not specified & $\mathrm{NA} \dagger$ \\
\hline \multicolumn{7}{|c|}{$\begin{array}{l}\text { All percentage values are expressed as volume } \% \text { unless otherwise noted. } \\
* \text { Accuracy: } \pm 5 \% \text { of reading for } 41-70 \mathrm{~mm} \mathrm{Hg}, \pm 8 \% \text { of reading for } 71-100 \mathrm{~mm} \mathrm{Hg}, \pm 10 \% \text { of reading for } 101-150 \mathrm{~mm} \mathrm{Hg} \text {. } \\
\dagger \text { Not applicable because the ventilator is not set up to measure oxygen consumption, although as a safety feature, an } \mathrm{O}_{2} \text { sensor is incorporated, but only to verify oxygen delivery to the patient. } \\
\ddagger \text { Accuracy: } \pm 5 \% \text { of the measured value in the range } 41-100 \mathrm{~mm} \mathrm{Hg} \text {. } \\
\S \pm 15 \% \text { or } 15 \mathrm{~mL} \text { for } \mathrm{F}_{\mathrm{IO}_{2}} 0.65-0.85 \text {. } \\
\text { NDIR = non-dispersive infrared }\end{array}$} \\
\hline
\end{tabular}

gas flow. The gas concentrations and inspired and expired gas volumes are integrated to yield $\dot{\mathrm{V}}_{\mathrm{O}_{2}}$ and $\dot{\mathrm{V}}_{\mathrm{CO}_{2}}$ values. Gas exchange monitoring capabilities, primarily $\dot{\mathrm{V}}_{\mathrm{CO}_{2}}$ monitoring, are incorporated into many modern mechanical ventilators used in critical care. A summary of a selection of devices available in the United States is provided in Table 1.

\section{Potential Uses and Indications}

In nutrition applications, an indirect calorimeter or a mechanical ventilator with gas exchange capabilities (see Table 1) measures both $\dot{\mathrm{V}}_{\mathrm{O}_{2}}$ and $\dot{\mathrm{V}}_{\mathrm{CO}_{2}}$ as a noninvasive means of determining substrate oxidation and rate of energy expenditure (EE). ${ }^{29}$ The modified Weir equation is used to extract a patient's EE based upon $\dot{\mathrm{V}}_{\mathrm{O}_{2}}$ and $\dot{\mathrm{V}}_{\mathrm{CO}_{2}}{ }^{30,31}$.

$$
\mathrm{EE}=\left[3.941\left(\dot{\mathrm{V}}_{\mathrm{O}_{2}}\right)+1.106\left(\dot{\mathrm{V}}_{\mathrm{CO}_{2}}\right)\right] \times 1,440
$$

Modern indirect calorimetry devices are able to detect $\dot{\mathrm{V}}_{\mathrm{O}_{2}}$ and $\dot{\mathrm{V}}_{\mathrm{CO}_{2}}$ in patients during mechanical ventilation, during spontaneous breathing, and even during noninvasive ventilation. ${ }^{32}$ An indirect calorimeter is recommended to help titrate energy prescriptions in critically ill children. ${ }^{33}$ Tailoring nutrient intake to actual patient needs is especially important in this population, since children are at a high risk of nutrition deficiency due to high energy demand and relatively small energy reserves. ${ }^{34-36}$

Recently, methods have been described and validated to simplify the measurement of energy expenditure by requiring only $\dot{\mathrm{V}}_{\mathrm{CO}_{2}}$ measurements in children. ${ }^{37,38}$ These methods as- sume that the respiratory quotient $\left(\dot{\mathrm{V}}_{\mathrm{CO}_{2}} / \dot{\mathrm{V}}_{\mathrm{O}_{2}}\right)$ is equal to 0.89 and modifies the Weir equation to yield the following,

$$
\mathrm{EE}=5.534\left(\dot{\mathrm{V}}_{\mathrm{CO}_{2}}\right) \times 1,440
$$

where $\dot{\mathrm{V}}_{\mathrm{CO}_{2}}$ is in $\mathrm{L} / \mathrm{min}$, and 1,440 corresponds to the number of minutes in a day. EE is expressed in $\mathrm{kcal} / \mathrm{d}$.

The $\dot{\mathrm{V}}_{\mathrm{CO}_{2}}$ EE equation has important benefits over traditional indirect calorimetry methods due to the fact $\dot{\mathrm{V}}_{\mathrm{CO}_{2}}$ measurements are more readily available (especially since many ventilators offer integrated $\dot{\mathrm{V}}_{\mathrm{CO}_{2}}$ sensors only and not $\dot{\mathrm{V}}_{\mathrm{O}_{2}}$ ) and therefore may be able to extend the benefits of EE monitoring to a wider patient population. However, an important limitation is the error introduced if the patient's actual respiratory quotient (RQ) deviates from the assumed value; the method should provide EE estimates that are within $\pm 10 \%$ for an RQ range of $0.79-1.02 .{ }^{37}$ Continuously estimating $\mathrm{EE}$ from $\dot{\mathrm{V}}_{\mathrm{CO}_{2}}$ measurements may allow clinicians to identify gross over- or underfeeding. Overfeeding may be especially harmful in patients with severe respiratory insult. If energy intake exceeds a patient's requirement, an excessive amount of $\mathrm{CO}_{2}$ is produced and must be eliminated, resulting in increased respiratory work or elevated $\mathrm{P}_{\mathrm{aCO}_{2}}$. Although data have demonstrated that overfeeding adult subjects with COPD results in significant respiratory deterioration, and cumulative energy imbalances have been reported in the pediatric ICU, overfeeding is probably under-recognized, and investigations in this area are needed. ${ }^{39,40}$

Other potential applications of $\dot{\mathrm{V}}_{\mathrm{CO}_{2}}$ monitoring include titration of end-expiratory pressure during critical illness, 
titration of minute ventilation during severe obstruction, and response to pulmonary vasodilation therapy. In an experimental model of pediatric lung disease, Hanson et al ${ }^{41,42}$ demonstrated that maximizing the volume of $\mathrm{CO}_{2}$ eliminated per breath was associated with maximal pulmonary recruitment. The physiologic rationale for the highest $\mathrm{CO}_{2}$ elimination being associated with optimal PEEP is that it represents the balance between atelectasis and overdistention. During marked atelectasis, lung units cease participating in gas exchange, since no gas is able to interface with blood (shunting). Consequently, the efficiency of ventilation is reduced and manifests as a reduction in $\dot{\mathrm{V}}_{\mathrm{CO}_{2}}$ (or $\mathrm{CO}_{2}$ volume/breath). On the other hand, as pressure and volume in the lungs are increased to the point that blood flow is impeded, $\dot{\mathrm{V}}_{\mathrm{CO}_{2}}$ (or $\mathrm{CO}_{2}$ volume/breath) decreases as a result of increased dead-space ventilation. Importantly, it is difficult to parse specific underlying pathophysiology (ie, shunt vs dead space) from assessing $\dot{\mathrm{V}}_{\mathrm{CO}_{2}}$ alone; therefore, interpretation of these data must be done with caution. During severe obstruction, $\dot{\mathrm{V}}_{\mathrm{CO}_{2}}$ can be utilized to titrate inspiratory and expiratory times to maximize ventilation, since, during severe obstruction, the optimal change in ventilator support may be to decrease breathing frequency to facilitate alveolar emptying. Although the rationale for this application is sound, there are limited data describing it.

\section{Limitations and Future Directions of Investigation}

Limitations of gas exchange monitoring include errors in calibration and selection of an appropriate airway adapter based on patient size. Further, some methods require more frequent or extensive calibration, and failing to follow manufacturer recommendations may result in erroneous values. In nutrition applications, timing of study and achievement of steady state are essential to minimize error. When applying the $\dot{\mathrm{V}}_{\mathrm{CO}_{2}}$ EE equation, clinicians must be mindful that the assumed RQ of the equation and significant deviations from this may yield inaccurate results. In titration of ventilation and assessment of therapy, it is important to interpret $\dot{\mathrm{CO}}_{\mathrm{CO}_{2}}$ data alongside changes in clinical condition and achievement of stability/steady state. ${ }^{43}$ Changes in level of consciousness, agitation, temperature, feeding, and other parameters can affect $\dot{\mathrm{C}}_{\mathrm{CO}_{2}}$ and must be carefully assessed to safely interpret data at the bedside. ${ }^{44,45}$ Since many manufacturers do not provide accuracy and precision data for gas exchange devices, clinicians must rely on independently published data and/or personally conducted bench tests.

\section{Near-Infrared Spectroscopy}

\section{Function}

A near-infrared spectroscopy device leverages the relative permeability of biologic tissues to near-infrared light.
The device uses a number of near-infrared light emitterreceiver distances and wavelength combinations (typically from 650 to $950 \mathrm{~nm}$ ) to estimate the relative concentrations of both deoxygenated and oxygenated hemoglobin. A modification of the Beer-Lambert law models the relationship between the near-infrared light absorption and the concentration of the chromophore in the tissues (Equation 4). A chromophore includes the portions of a molecule that are responsible for its color. In the specific context of near-infrared spectroscopy, it is the portion of the hemoglobin molecule that absorbs near-infrared light, a property that changes when oxygen is added or removed.

$$
\mathrm{A}=\alpha \mathrm{BdC}+\mathrm{G}
$$

where $\mathrm{A}$ is the optical density attenuation, $\alpha$ is the absorption coefficient of a chromophore at a specific wavelength $(\mathrm{L} / \mu \mathrm{mol} / \mathrm{cm}), \mathrm{B}$ is the differential path length factor, $\mathrm{d}$ is distance between the near-infrared emitter and receiver, $\mathrm{C}$ is the concentration of the chromophore $(\mathrm{mmol} / \mathrm{L})$, and $\mathrm{G}$ is a term that represents the loss of near-infrared that occurs due to scattering in the tissues. The requirement to measure the differential path length of light (term B in Equation 4) can be obviated by assessing only the ratio of oxyhemoglobin $\left(\mathrm{HbO}_{2}\right)$ to total hemoglobin $\left(\mathrm{Hb}_{\text {tot }}\right)$. This offers a substantial methodological simplification that improves the reliability of measurements. The ratio (percentage) calculation is as follows,

$$
\mathrm{RSO}_{2}=\mathrm{HbO}_{2} /\left(\mathrm{HbO}_{2}+\mathrm{Hb}_{\text {tot }}\right)
$$

where $\mathrm{RSO}_{2}$ is the regional oxygen saturation.

\section{Potential Uses and Indications}

Near-infrared spectroscopy is a noninvasive method of assessing oxygen supply and consumption balance in a tissue (such as the brain) and can be used to estimate blood flow. ${ }^{46}$ A common application is the measurement of regional oxygen saturation in the brain. In this case, a nearinfrared spectroscopy probe is affixed to the patient's forehead with relative ease. In infants, brain injury is often related to cerebral oxygenation and cerebral blood flow disturbances. ${ }^{47}$ Examples of such injury include hypoxicischemic encephalopathy, intraventricular hemorrhages, and perinatal arterial ischemic stroke. Devices available on the market provide regional oxygen saturation. Cerebral brain regional oxygen saturation is a venous representation of cerebral oxygenation and is a gross indication of $\mathrm{O}_{2}$ reserve and potentially ischemic risk. As brain regional oxygen saturation decreases, the probability of ischemic injury increases. An average cerebral brain regional oxygen saturation $<65 \%$ has also been associated with hy- 
Table 2. Selection of Available Devices That Measure Transcutaneous $\mathrm{CO}_{2}$

\begin{tabular}{|c|c|c|c|c|c|}
\hline Device and Manufacturer & $\begin{array}{l}\text { Response } \\
\text { Time, s }\end{array}$ & $\begin{array}{c}\mathrm{CO}_{2} \text { Specification } \\
\text { Range, mm Hg } \\
\text { (Accuracy) }\end{array}$ & Operating Temperature, ${ }^{\circ} \mathrm{C}$ & $\begin{array}{l}\text { Sensor Calibration } \\
\text { Frequency, h }\end{array}$ & $\begin{array}{l}\text { Sensor Membrane } \\
\text { Change Frequency }\end{array}$ \\
\hline $\begin{array}{l}\text { V-Sign digital monitor (SenTec, } \\
\text { Therwil, Switzerland) }\end{array}$ & $<75$ & 0-200 (not specified) & 37-44.5 (user-configurable) & 12 & $\begin{array}{l}\text { Up to } 6 \text { weeks ( } 4 \\
\text { weeks is default) }\end{array}$ \\
\hline $\begin{array}{l}\text { TCM CombiM (Radiometer, } \\
\text { Brønshøj, Denmark) }\end{array}$ & $<60$ & 5-200 (not specified) & 37-44 (user-configurable) & 12 & 2 weeks \\
\hline
\end{tabular}

perlactatemia and may be a global hypoperfusion indicator when caused by low cardiac output. ${ }^{48}$ Further, decreased brain regional oxygen saturation has been associated with 1-y developmental outcomes in children following cardiac surgery. ${ }^{49}$ Application of near-infrared spectroscopy in the delivery room may reduce the propensity of cerebral hypoxia during the transition period as infants adapt to extrauterine life. ${ }^{50}$ In the first $72 \mathrm{~h}$ of life, brain regional oxygen saturation has been observed to decrease until $\sim 12 \mathrm{~h}$ and then gradually increase after 18 h. ${ }^{51}$ Importantly, brain regional oxygen saturation measurement may aid in reducing the incidence of cerebral hypo- and hyperoxygenation by guiding oxygen therapy. ${ }^{52}$ It has also been demonstrated that a higher rate of hypoxia incidence is detected with cerebral brain regional oxygen saturation compared with peripheral oxygen saturation and blood pressure in neonates in the perioperative period. ${ }^{53}$ Near-infrared spectroscopy devices are available from several manufacturers, and most provide patient-specific sensors (neonatal and adult).

In smaller infants, the probing of other organs is possible (albeit with significant potential for error), since they are closer to the surface compared with older children and adults. ${ }^{54}$ Although further study is required, regional oxygen saturation may play a role in quantifying response to blood transfusion..$^{55}$ Oxygen saturation measurements may also play a role in assessing severity of apnea and bradycardia events, ${ }^{56}$ early diagnosis of severe patent ductus arteriosus, ${ }^{57}$ and identification of possible derangements in cerebral autoregulation in neonates with respiratory distress syndrome. ${ }^{58}$

\section{Limitations and Future Directions of Investigation}

Limitations of near-infrared spectroscopy include inaccurate measurements with inappropriate or suboptimal probe placement. Affixing the probe to hematomas, bony or fatty areas as well as applying excessive pressure should be avoided. Another important limitation is the lack of large observational trials quantifying oxygen saturation values for tissue in various patient cohorts (pre-term, infants, or children). Further, although initial reports of potential applications of near-infrared spectroscopy are promising, these studies, on average, include relatively small populations, and broader application to a more heterogeneous population has not been adequately described in the literature.

Therefore, further investigation is required for near-infrared spectroscopy. Normative data for select patient populations needs to be described as well as derivation and validation of values that can be used prognostically or for assessing response to therapy. Importantly, the application of near-infrared spectroscopy monitoring for infants receiving extracorporeal membrane oxygenation should be investigated because it may offer a surrogate assessment of organ perfusion and relative health. In general, nearinfrared spectroscopy is attractive, since it offers a convenient noninvasive interface with the potential to support bedside care. However, caution should be used with the device at this stage, since the evidence supporting its use is very limited in pediatric patients.

\section{Transcutaneous Carbon Dioxide and Oxygen}

\section{Function}

Methods for transcutaneous monitoring of $\mathrm{CO}_{2}\left(\mathrm{P}_{\mathrm{tcCO}_{2}}\right)$ and $\mathrm{O}_{2}\left(\mathrm{P}_{\mathrm{tcO}_{2}}\right)$ were first described in the mid-to-late twentieth century. ${ }^{59,60}$ In brief, a sensor is affixed to the skin, which is warmed to $\sim 37-44^{\circ} \mathrm{C}$. The increased temperature causes vasodilation of the capillary bed in order to facilitate diffusion of gases to the location of the sensor membrane where the gases are measured. $\mathrm{P}_{\mathrm{tcCO}}$ and $\mathrm{P}_{\mathrm{tcO}}$ provide estimates of $\mathrm{P}_{\mathrm{aCO}}$ and $\mathrm{P}_{\mathrm{aO}}$, respectively.

\section{Potential Uses and Indications}

Partial pressures are overestimated with transcutaneous compared with arterial samples due to metabolism at the site of the sensor and other factors. ${ }^{61}$ Therefore, correction factors have been proposed to compensate for this. ${ }^{62}$ The technology has primarily been utilized in the neonatal population, but recent applications have arisen in pediatric ventilatory support. A summary of a selection of available devices that measure $\mathrm{P}_{\mathrm{tcCO}_{2}}$ is provided in Table 2 .

High-frequency oscillatory ventilation (HFOV) remains an important adjunct therapy for children with respiratory failure. ${ }^{63}$ Due to the high velocity, oscillatory flow pattern, 
$\mathrm{P}_{\mathrm{ETCO}}$ is not feasible during HFOV. $\mathrm{P}_{\mathrm{tcCO}_{2}}$ has been shown to be feasible in this population, but with important limitations. ${ }^{64}$ Limitations in the context of HFOV include error due to edema and changes in tissue perfusion. Nonetheless, the ability to dynamically and continuously assess ventilation and oxygenation during HFOV is attractive, and transcutaneous monitoring, when applied correctly and assessed carefully, may provide important clinical insights. In a cohort of children receiving long-term noninvasive ventilation, Felemban et al ${ }^{65}$ demonstrated the correlation between values of $\mathrm{P}_{\mathrm{tcCO}_{2}}$ collected at home and in the hospital. The authors report a statistically significant, albeit modest, correlation between $\mathrm{P}_{\mathrm{tcCO}_{2}}$ at home and in the hospital ( $\mathrm{r}=0.647, P=.037)$. There are important limitations to the study, and future work should assess the agreement between $\mathrm{P}_{\mathrm{tcCO}} / \mathrm{P}_{\mathrm{tcO}_{2}}$ and arterial values collected simultaneously.

\section{Limitations and Future Directions of Investigation}

Important considerations when using transcutaneous monitoring systems include the need for frequent calibration (although vastly improved compared with previous generations), replacement of sensor membranes, assessment of skin integrity under the sensor, and the potential for erroneous measurements as a function of changes in or poor tissue perfusion. ${ }^{61,66}$ Further work is needed to demonstrate the agreement between $\mathrm{P}_{\mathrm{tcCO}}$ and $\mathrm{P}_{\mathrm{aCO}}$ and clinical applicability of the measurements during HFOV and noninvasive ventilation. Additionally, technological advancements, including the utility of simultaneous multisite probe placement, are forthcoming.

\section{Pulse Oximetry}

The estimation of arterial oxygen saturation by pulse oximetry $\left(\mathrm{S}_{\mathrm{pO}_{2}}\right)$ allows for the continuous estimation of oxygenation and detection of hypoxemia. The device is routinely applied to pediatric patients throughout the hospital and has been referred to as the "fifth vital sign." 67 Assessment of hypoxemia is historically difficult, since various factors affect reliability, including tissue perfusion, hemoglobin concentration, tissue pigmentation, and ambient lighting. A brief overview of the technology and some of the issues are noted below.

\section{Function}

Pulse oximetry function shares many features similar to near-infrared spectroscopy and transcutaneous monitoring. Pulse oximetry leverages the specific spectroscopic principles of oxygenated and deoxygenated hemoglobin (oxyhemoglobin and deoxyhemoglobin) when red and infrared light is introduced to provide a measure of blood oxygenation; absorption of red and infrared light differs between hemoglobin loaded with and without oxygen. Deoxyhemoglobin is characterized by increased red light absorption (wavelengths 600-700 nm), and oxyhemoglobin tends to absorb light in the infrared spectrum (700-1,000 nm; Fig. 6). ${ }^{69,70}$ The ratio of red to infrared light transmission is calculated and converted to $\mathrm{S}_{\mathrm{pO}_{2}}$ by a Beer-Lambert law lookup table.

\section{Potential Uses and Indications}

There is a paucity of normative $\mathrm{S}_{\mathrm{pO}_{2}}$ data for acutely and critically ill children. However, in healthy children, mean $\mathrm{S}_{\mathrm{pO}_{2}}$ levels at sea level are between 97 and $99 \% .71,72 \mathrm{~S}_{\mathrm{pO}_{2}}$ decreases with elevation as a function of reduced atmospheric pressure. Pulse oximetry should be applied in all cases where hypoxemia is suspected. This means that in most centers, pulse oximetry use is nearly ubiquitous. In particular, $\mathrm{S}_{\mathrm{pO}_{2}}$ can be used identify severity of illness for conditions associated with ventilation/perfusion mismatch. Examples include asthma, acute and chronic lung disease, acute bronchiolitis, and pneumonia. ${ }^{73-76}$ Asthma severity has been associated with $\mathrm{S}_{\mathrm{pO}_{2}}$ : mild, $>95 \%$; moderate, 90-95\%; severe, $<90 \% .{ }^{76}$ During asthma exacerbation, an $\mathrm{S}_{\mathrm{pO}_{2}}$ of $>94 \% 1 \mathrm{~h}$ after bronchodilator treatment in the emergency department has been shown to be a reasonable predictor of need for hospitalization. ${ }^{77,78}$ Pulse oximetry is also used for the diagnosis and to stratify severity of illness in pediatric ARDS by the application of the oxygen saturation index $\left(\left[\mathrm{F}_{\mathrm{IO}_{2}} \times\right.\right.$ mean airway pressure $\left.\times 100] / \mathrm{S}_{\mathrm{pO}_{2}}\right) .{ }^{79} \mathrm{~S}_{\mathrm{pO}_{2}}$ is not a sensitive metric of severity of proximal airway obstruction (eg, foreign body aspiration, laryngothracheitis). In this case, capnography should be applied to patients with suspected upper-airway obstruction. Pulse oximetry also plays an important role in screening for congenital heart disease in the newborn. ${ }^{80}$ The role of continuous $\mathrm{S}_{\mathrm{pO}_{2}}$ monitoring is also important in the home during prolonged invasive mechanical ventilation and is an important part of telemedicine. ${ }^{81}$

\section{Limitations and Future Directions of Investigation}

Limitations of pulse oximetry primarily derive from numeric error introduced as a function of clinical circumstances. Motion artifact can affect the signal/noise ratio and subsequently provide incorrectly low values. ${ }^{82}$ However, hardware and signal processing improvements of some devices have improved the performance of pulse oximetry during motion and provided clinicians with artifact alerts. ${ }^{83}$ A decrease in perfusion to the site at which the probe is affixed and dark skin pigmentation decrease the calculated $\mathrm{S}_{\mathrm{pO}_{2}}$ value, especially in cases where the measured $\mathrm{S}_{\mathrm{pO}_{2}}$ is $<80 \% .{ }^{84-86}$ Methemoglobin absorbs roughly the same amount of light in both the red and infrared wavelength, and therefore its presence in the blood, such as during methomoglobinemia, confounds an accurate assessment of 


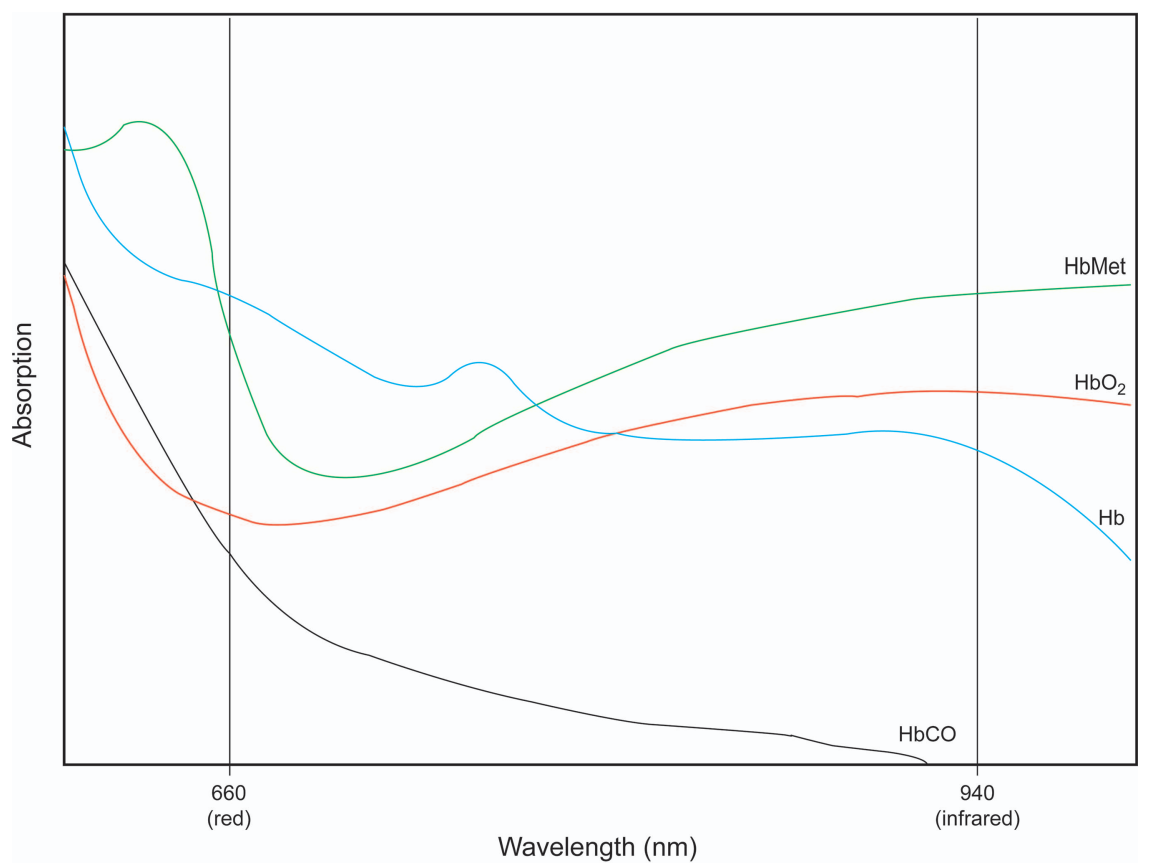

Fig. 6. Spectra of the relative absorption of oxyhemoglobin $\left(\mathrm{HbO}_{2}\right)$, deoxyhemoglobin $(\mathrm{Hb})$, methemoglibin (HbMet), and carboxyhemoglibin $(\mathrm{HbCO})$. The vertical lines represent the wavelengths often incorporated into bedside pulse oximeters. From Reference 68 , with permission.

$\mathrm{S}_{\mathrm{pO}_{2}}$ (see also Fig. 6.). ${ }^{87}$ Some modern devices have sought to utilize non-standard wavelength light to discriminate methemoglobin and carboxyhemoglobin from oxyhemoglobin through co-oximetry. An important practice to assess for these non-standard forms of hemoglobin includes the calculation of the difference between the $\mathrm{S}_{\mathrm{pO}_{2}}$ value and the $\mathrm{S}_{\mathrm{aO}_{2}}$ value. If the difference is $>5 \%$, one should consider the presence of methemoglobin and/or carboxyhemoglobin. ${ }^{88}$ In this case, further testing may be indicated. In the future, research efforts to automate the interpretation of $\mathrm{S}_{\mathrm{pO}_{2}}$ and provide context analysis (interpreting the value not on its own but in the context of the patient's age, disease, and other medical information) and provide decision support should be pursued in the pediatric population.

\section{Electrical Impedance Tomography}

\section{Function}

Electrical impedance tomography (EIT) does not offer direct measurement of oxygenation and ventilation (by providing a surrogate for $\mathrm{O}_{2}$ and $\mathrm{CO}_{2}$ ). Rather, it provides information regarding ventilation and perfusion matching. EIT is a real-time imaging modality that is noninvasive and radiation-free. ${ }^{89}$ In tissue, electrical current is conducted based on ion concentration and tissue fluid volumes. Current does not readily pass through air and therefore travels along the alveolar septa tissue. As the lungs inflate and the alveoli expand, the distance that the current must travel increases, increasing impedance. Impedance is the ratio of voltage to current, and images of regional impedance changes are displayed on the device. Primarily, EIT images are relative and based upon deviation from a baseline, since absolute imaging requires very detailed spatial and geometric information about lung, tissue, and electrode locations and sizes. ${ }^{90-93}$

Mathematically, EIT is an inverse problem (meaning that, in the context of pulmonary imaging, images are generated from measurements taken outside of the body) and severely ill-posed (a mathematical problem with many potential solutions). For these reasons, a number of algorithms have been developed to adequately and accurately reconstruct lung images based on surface measurements.

The EIT system is composed of a series of electrodes attached circumferentially around the chest. The number of electrodes can vary, but typically 16 or 32 are utilized for a single-plane or 32 electrodes or more for a dual-plane setup. Common settings for data collection are to inject a very small alternating current $(\sim 5 \mathrm{~mA})$ at a frequency of $50 \mathrm{kHz} .{ }^{94}$

\section{Potential Uses and Indications}

Some applications of EIT in both humans and experimental models have highlighted the assessment of regional distribution of ventilation for PEEP titration, ${ }^{95-97}$ assessing differences between ventilator modes, ${ }^{98}$ position changes, ${ }^{99}$ 
detection of pneumothorax, ${ }^{100,101}$ and quantification of pulmonary edema. ${ }^{102}$ Further delineation of these studies is beyond the scope of the present review. Importantly, only a limited number of the investigations have been conducted in pediatric populations. In the context of oxygen and carbon dioxide measurement, EIT cannot offer specific values. However, real-time quantification of ventilation and perfusion as measured by EIT is emerging as a bedside tool. Although not a direct measurement of $\mathrm{O}_{2}$ and $\mathrm{CO}_{2}$, real-time quantification of regional perfusion and ventilation may offer important insights into disease and offer a means of assessing interventions aimed at improving gas exchange during critical illness. Although studies have demonstrated the technical feasibility of the technology for quantifying perfusion distribution in humans, limited data exist for pediatric subjects. ${ }^{103,104}$ It is well known that hydrostatic pressure gradients are an important determinant of pulmonary perfusion in adults. However, less is known about infant and child perfusion distribution and dynamic ventilation-perfusion matching. Carlisle et al ${ }^{105}$ quantified the regional and gravity-dependent nature of blood perfusion in the infant chest and showed that, unlike adults, infants have greater perfusion of the non-dependent right hemithorax. These findings may help to guide ventilation strategies tailored to this population that seek to optimize ventilation-perfusion matching while reducing lung injury risk.

\section{Limitations and Future Directions of Investigation}

Presently, EIT is only used in a research context in the United States. Its use is not widespread and is significantly hindered by a lack of FDA-cleared devices available for routine clinical monitoring. Even if the device were available, pragmatic factors need to be assessed before the technology could be applied as suggested. First, long-term reproducibility of images should be demonstrated. Reproducible electrode band placement is essential to assess the same lung region from day to day. As adoption becomes more widespread, an increased number of clinicians applying and troubleshooting the device may lead to variation in placement and confound findings. Second, in cases where the device is applied continuously for the duration of mechanical ventilation or ICU stay, patient tolerance needs to be assessed. Third, large randomized controlled clinical trials should be constructed to demonstrate the superiority of regional distribution monitoring and targeted ventilation strategies compared with standard care. Although current data are very limited and further work (both on the corporate and research side) are needed, EIT is an attractive technology due to its noninvasive nature and potential to glean important real-time changes in ventilation and perfusion.

\section{Summary}

The noninvasive measurement of $\mathrm{CO}_{2}$ and $\mathrm{O}_{2}$ is a pillar of respiratory support and essential to offer high-quality care to pediatric subjects. With some newer technology (EIT and near-infrared spectroscopy), important work in validation and clinical decision-making is needed before widespread adoption of the methods can be recommended. However, both are attractive, since they are noninvasive and easy to apply and may offer important insights that can provide decision support. In the case of technologies that have been a part of respiratory care for decades (capnography, gas exchange monitoring, transcutaneous monitoring, and pulse oximetry), important refinements to technology and the development of new methods and applications may enable the application of the devices to a wider and more comprehensive pediatric patient population while enabling individual care to be optimized.

\section{REFERENCES}

1. Siobal MS. Monitoring exhaled carbon dioxide. Respir Care 2016; 61(10):1397-1416.

2. Pascucci RC, Schena JA, Thompson JE. Comparison of a sidestream and mainstream capnometer in infants. Crit Care Med 1989; 17(6):560-562.

3. Singh BS, Gilbert U, Singh S, Govindaswami B. Sidestream microstream end tidal carbon dioxide measurements and blood gas correlations in neonatal intensive care unit. Pediatr Pulmonol 2013; 48(3):250-256.

4. Breen PH, Mazumdar B, Skinner SC. Capnometer transport delay: measurement and clinical implications. Anesth Analg 1994;78(3): 584-586.

5. Thompson JE, Jaffe MB. Capnographic waveforms in the mechanically ventilated patient. Respir Care 2005;50(1):100-108; discussion 108-109.

6. Hosono S, Inami I, Fujita H, Minato M, Takahashi S, Mugishima $\mathrm{H}$. A role of end-tidal $\mathrm{CO}(2)$ monitoring for assessment of tracheal intubations in very low birth weight infants during neonatal resuscitation at birth. J Perinat Med 2009;37(1):79-84.

7. Salthe J, Kristiansen SM, Sollid S, Oglaend B, Søreide E. Capnography rapidly confirmed correct endotracheal tube placement during resuscitation of extremely low birthweight babies $(<1000 \mathrm{~g})$. Acta Anaesthesiol Scand 2006;50(8):1033-1036.

8. Bhende MS. End-tidal carbon dioxide monitoring in pediatrics: clinical applications. J Postgrad Med 2001;47(3):215-218.

9. Bhende MS, Thompson AE. Evaluation of an end-tidal $\mathrm{CO}_{2}$ detector during pediatric cardiopulmonary resuscitation. Pediatrics 1995; 95(3):395-399.

10. Singh S, Allen WD, Jr., Venkataraman ST, Bhende MS. Utility of a novel quantitative handheld microstream capnometer during transport of critically ill children. Am J Emerg Med 2006;24(3):302-307.

11. Mehta H, Kashyap R, Trivedi S. Correlation of end tidal and arterial carbon dioxide levels in critically Ill neonates and children. Indian J Crit Care Med 2014;18(6):348-353.

12. Lightdale JR, Goldmann DA, Feldman HA, Newburg AR, DiNardo JA, Fox VL. Microstream capnography improves patient monitoring during moderate sedation: a randomized, controlled trial. Pediatrics 2006;117(6):e1170-e1178.

13. Coates BM, Chaize R, Goodman DM, Rozenfeld RA. Performance of capnometry in non-intubated infants in the pediatric intensive care unit. BMC Pediatr 2014;14:163.

14. McSwain SD, Hamel DS, Smith PB, Gentile MA, Srinivasan S, Meliones JN, Cheifetz IM. End-tidal and arterial carbon dioxide measurements correlate across all levels of physiologic dead space. Respir Care 2010;55(3):288-293. 
15. Almeida-Junior AA, da Silva MT, Almeida CC, Ribeiro JD. Relationship between physiologic deadspace/tidal volume ratio and gas exchange in infants with acute bronchiolitis on invasive mechanical ventilation. Pediatr Crit Care Med 2007;8(4):372-377.

16. Bhalla AK, Belani S, Leung D, Newth CJ, Khemani RG. Higher dead space is associated with increased mortality in critically ill children. Crit Care Med 2015;43(11):2439-2445.

17. Hubble CL, Gentile MA, Tripp DS, Craig DM, Meliones JN, Cheifetz IM. Deadspace to tidal volume ratio predicts successful extubation in infants and children. Crit Care Med 2000;28(6):2034-2040.

18. Yehya N, Bhalla AK, Thomas NJ, Khemani RG. Alveolar dead space fraction discriminates mortality in pediatric acute respiratory distress syndrome. Pediatr Crit Care Med 2016;17(2):101-109.

19. Bhalla AK, Rubin S, Newth CJ, Ross P, Morzov R, Soto-Campos G, Khemani R. Monitoring dead space in mechanically ventilated children: volumetric capnography versus time-based capnography. Respir Care 2015;60(11):1548-1555.

20. Bourgoin P, Baudin F, Brossier D, Emeriaud G, Wysocki M, Jouvet P. Assessment of Bohr and Enghoff dead space equations in mechanically ventilated children. Respir Care 2017;62(4):468-474.

21. Langhan ML, Li FY, Lichtor JL. Respiratory depression detected by capnography among children in the postanesthesia care unit: a cross-sectional study. Paediatr Anaesth 2016;26(10):1010-1017.

22. Miller KM, Kim AY, Yaster M, Kudchadkar SR, White E, Fackler J, Monitto CL. Long-term tolerability of capnography and respiratory inductance plethysmography for respiratory monitoring in pediatric patients treated with patient-controlled analgesia. Paediatr Anaesth 2015;25(10):1054-1059.

23. Langhan ML, Li FY, Lichtor JL. The impact of capnography monitoring among children and adolescents in the postanesthesia care unit: a randomized controlled trial. Paediatr Anaesth 2017;27(4):385-393.

24. Hatlestad D. Capnography as a predictor of the return of spontaneous circulation. Emerg Med Serv 2004;33(8):75-80.

25. Hartmann SM, Farris RW, Di Gennaro JL, Roberts JS. Systematic review and meta-analysis of end-tidal carbon dioxide values associated with return of spontaneous circulation during cardiopulmonary resuscitation. J Intensive Care Med 2015;30(7):426-435.

26. Hamrick JL, Hamrick JT, Lee JK, Lee BH, Koehler RC, Shaffner $\mathrm{DH}$. Efficacy of chest compressions directed by end-tidal $\mathrm{CO}_{2}$ feedback in a pediatric resuscitation model of basic life support. J Am Heart Assoc 2014;3(2):e000450. doi: 10.1161/JAHA.113.000450.

27. Pokorná M, Necas E, Kratochvíl J, Skripský R, Andrlík M, Franek O. A sudden increase in partial pressure end-tidal carbon dioxide $(\mathrm{P}(\mathrm{ET}) \mathrm{CO}(2))$ at the moment of return of spontaneous circulation. J Emerg Med 2010;38(5):614-621.

28. Kazemi M, Bala Krishnan M, Aik Howe T. Frequency analysis of capnogram signals to differentiate asthmatic and non-asthmatic conditions using radial basis function neural networks. Iran J Allergy Asthma Immunol 2013;12(3):236-246.

29. Ferrannini E. The theoretical bases of indirect calorimetry: a review. Metabolism 1988;37(3):287-301.

30. Weir JB. New methods for calculating metabolic rate with special reference to protein metabolism: 1949. Nutrition 1990;6(3):213-221.

31. Weir JB. New methods for calculating metabolic rate with special reference to protein metabolism. J Physiol 1949;109(1):1-9.

32. Smallwood CD, Mehta NM. Accuracy of gas exchange monitoring during noninvasive ventilation: an in vitro metabolic simulation. JPEN J Parenter Enteral Nutr 2014;38(1):86-91.

33. Mehta NM, Compher C, A.S.P.E.N. Board of Directors. A.S.P.E.N. clinical guidelines. nutrition support of the critically ill child. JPEN J Parenter Enteral Nutr 2009;33(3):260-276.

34. Jaksic T. Effective and efficient nutritional support for the injured child. Surg Clin North Am 2002;82(2):379-391, vii.
35. Chwals WJ. Overfeeding the critically ill child: fact or fantasy? New Horiz 1994;2(2):147-155.

36. Klein S, Kinney J, Jeejeebhoy K, Alpers D, Hellerstein M, Murray M, Twomey P. Nutrition support in clinical practice: review of published data and recommendations for future research directions. Clin Nutr 1997;16(4):193-218.

37. Mehta NM, Smallwood CD, Joosten KF, Hulst JM, Tasker RC, Duggan CP. Accuracy of a simplified equation for energy expenditure based on bedside volumetric carbon dioxide elimination measurement: a two-center study. Clin Nutr 2015;34(1):151-155.

38. Kerklaan D, Augustus ME, Hulst JM, van Rosmalen J, Verbruggen SC, Joosten KF. Validation of ventilator-derived VCO measurements to determine energy expenditure in ventilated critically ill children. Clin Nutr 2017;36(2):452-457.

39. Efthimiou J, Mounsey PJ, Benson DN, Madgwick R, Coles SJ, Benson MK. Effect of carbohydrate rich versus fat rich loads on gas exchange and walking performance in patients with chronic obstructive lung disease. Thorax 1992;47(6):451-456.

40. Mehta NM, Bechard LJ, Leavitt K, Duggan C. Cumulative energy imbalance in the pediatric intensive care unit: role of targeted indirect calorimetry. JPEN J Parenter Enteral Nutr 2009;33(3):336-344.

41. Hanson A, Göthberg S, Nilsson K, Larsson LE, Hedenstierna G. VTCO2 and dynamic compliance-guided lung recruitment in surfactant-depleted piglets: a computed tomography study. Pediatr Crit Care Med 2009;10(6):687-692.

42. Hanson A, Göthberg S, Nilsson K, Hedenstierna G. Lung aeration during ventilation after recruitment guided by tidal elimination of carbon dioxide and dynamic compliance was better than after endtidal carbon dioxide targeted ventilation: a computed tomography study in surfactant-depleted piglets. Pediatr Crit Care Med 2011; 12(6):e362-e368.

43. Smallwood CD, Mehta NM. Accuracy of abbreviated indirect calorimetry protocols for energy expenditure measurement in critically ill children. JPEN J Parenter Enteral Nutr 2012;36(6):693-699.

44. McClave SA, Spain DA, Skolnick JL, Lowen CC, Kieber MJ, Wickerham PS, et al. Achievement of steady state optimizes results when performing indirect calorimetry. JPEN J Parenter Enteral Nutr 2003;27(1):16-20.

45. Brandi LS, Bertolini R, Santini L, Cavani S. Effects of ventilator resetting on indirect calorimetry measurement in the critically ill surgical patient. Crit Care Med 1999;27(3):531-539.

46. van Bel F, Lemmers P, Naulaers G. Monitoring neonatal regional cerebral oxygen saturation in clinical practice: value and pitfalls. Neonatology 2008;94(4):237-244.

47. Alderliesten T, Lemmers PM, Smarius JJ, van de Vosse RE, Baerts W, van Bel F. Cerebral oxygenation, extraction, and autoregulation in very preterm infants who develop peri-intraventricular hemorrhage. J Pediatr 2013;162(4):698-704.e2.

48. Chakravarti SB, Mittnacht AJ, Katz JC, Nguyen K, Joashi U, Srivastava S. Multisite near-infrared spectroscopy predicts elevated blood lactate level in children after cardiac surgery. J Cardiothorac Vasc Anesth 2009;23(5):663-667.

49. Kussman BD, Wypij D, Laussen PC, Soul JS, Bellinger DC, DiNardo JA, et al. Relationship of intraoperative cerebral oxygen saturation to neurodevelopmental outcome and brain magnetic resonance imaging at 1 year of age in infants undergoing biventricular repair. Circulation 2010;122(3):245-254.

50. Pichler G, Urlesberger B, Baik N, Schwaberger B, Binder-Heschl $\mathrm{C}$, Avian A, et al. Cerebral oxygen saturation to guide oxygen delivery in preterm neonates for the immediate transition after birth: a 2-center randomized controlled pilot feasibility trial. J Pediatr 2016;170:73-78.e1-4. 


\section{Noninvasive Monitoring of Oxygen And Ventilation}

51. Takami T, Sunohara D, Kondo A, Mizukaki N, Suganami Y, Takei $\mathrm{Y}$, et al. Changes in cerebral perfusion in extremely LBW infants during the first $72 \mathrm{~h}$ after birth. Pediatr Res 2010;68(5):435-439.

52. van Vonderen JJ, Roest AA, Siew ML, Walther FJ, Hooper SB, te Pas AB. Measuring physiological changes during the transition to life after birth. Neonatology 2014;105(3):230-242.

53. Koch HW, Hansen TG. Perioperative use of cerebral and renal near-infrared spectroscopy in neonates: a 24-h observational study. Paediatr Anaesth 2016;26(2):190-198.

54. Vretzakis G, Georgopoulou S, Stamoulis K, Stamatiou G, Tsakiridis $\mathrm{K}$, Zarogoulidis P, et al. Cerebral oximetry in cardiac anesthesia. J Thorac Dis 2014;6(Suppl 1):S60-S69.

55. Seidel D, Bläser A, Gebauer C, Pulzer F, Thome U, Knüpfer M. Changes in regional tissue oxygenation saturation and desaturations after red blood cell transfusion in preterm infants. J Perinatol 2013; 33(4):282-287.

56. Pichler G, Urlesberger B, Müller W. Impact of bradycardia on cerebral oxygenation and cerebral blood volume during apnoea in preterm infants. Physiol Meas 2003;24(3):671-680.

57. Lemmers PM, Toet MC, van Bel F. Impact of patent ductus arteriosus and subsequent therapy with indomethacin on cerebral oxygenation in preterm infants. Pediatrics 2008;121(1):142-147.

58. Lemmers PM, Toet M, van Schelven LJ, van Bel F. Cerebral oxygenation and cerebral oxygen extraction in the preterm infant: the impact of respiratory distress syndrome. Exp Brain Res 2006;173(3):458-467.

59. Severinghaus JW, Bradley AF. Electrodes for blood $\mathrm{P}_{\mathrm{O}_{2}}$ and $\mathrm{P}_{\mathrm{CO}_{2}}$ determination. J Appl Physiol 1958;13(3):515-520.

60. Mindt W, Eberhard P. Electrochemical sensors for invasive and non-invasive monitoring of blood gases. Med Prog Technol 1982; 9(2):105-111.

61. Eberhard P. The design, use, and results of transcutaneous carbon dioxide analysis: current and future directions. Anesth Analg 2007; 105(6 Suppl):S48-S52.

62. Hazinski TA, Severinghaus JW. Transcutaneous analysis of arterial $\mathrm{P}_{\mathrm{CO}_{2}}$. Med Instrum 1982;16(3):150-153.

63. Rettig JS, Smallwood CD, Walsh BK, Rimensberger PC, Bachman $\mathrm{TE}$, Bollen $\mathrm{CW}$, et al. High-frequency oscillatory ventilation in pediatric acute lung injury: a multicenter international experience. Crit Care Med 2015;43(12):2660-2667.

64. Berkenbosch JW, Tobias JD. Transcutaneous carbon dioxide monitoring during high-frequency oscillatory ventilation in infants and children. Crit Care Med 2002;30(5):1024-1027.

65. Felemban O, Leroux K, Aubertin G, Miandy F, Damagnez F, Amorim $\mathrm{B}$, et al. Value of gas exchange recording at home in children receiving non-invasive ventilation. Pediatr Pulmonol 2011;46(8):802-808.

66. Restrepo RD, Hirst KR, Wittnebel L, Wettstein R. AARC clinical practice guideline: transcutaneous monitoring of carbon dioxide and oxygen: 2012. Respir Care 2012;57(11):1955-1962.

67. Mower WR, Sachs C, Nicklin EL, Baraff LJ. Pulse oximetry as a fifth pediatric vital sign. Pediatrics 1997;99(5):681-686.

68. König MW, Dolinski SY. A 74-year-old woman with desaturation following surgery. Chest 2003;123(2):613-616.

69. Sinex JE. Pulse oximetry: principles and limitations. Am J Emerg Med 1999;17(1):59-67.

70. Fouzas S, Priftis KN, Anthracopoulos MB. Pulse oximetry in pediatric practice. Pediatrics 2011;128(4):740-752.

71. Mau MK, Yamasato KS, Yamamoto LG. Normal oxygen saturation values in pediatric patients. Hawaii Med J 2005;64(2):42-45.

72. Laman M, Ripa P, Vince JD, Tefuarani N. Reference values for pulse oximetry in healthy children in coastal Papua New Guinea. P N G Med J 2009;52(1):8-12.

73. Mower WR, Sachs C, Nicklin EL, Safa P, Baraff LJ. Effect of routine emergency department triage pulse oximetry screening on medical management. Chest 1995;108(5):1297-1302.
74. Pavón D, Castro-Rodríguez JA, Rubilar L, Girardi G. Relation between pulse oximetry and clinical score in children with acute wheezing less than 24 months of age. Pediatr Pulmonol 1999;27(6):423-427.

75. Duke T, Subhi R, Peel D, Frey B. Pulse oximetry: technology to reduce child mortality in developing countries. Ann Trop Paediatr 2009;29(3):165-175.

76. National Asthma Education and Prevention Program. Expert panel report 3 (EPR-3): guidelines for the diagnosis and management of asthma-summary report 2007. J Allergy Clin Immunol 2007;120(5 Suppl):S94-S138.

77. Wright RO, Santucci KA, Jay GD, Steele DW. Evaluation of preand posttreatment pulse oximetry in acute childhood asthma. Acad Emerg Med 1997;4(2):114-117.

78. Kelly AM, Kerr D, Powell C. Is severity assessment after one hour of treatment better for predicting the need for admission in acute asthma? Respir Med 2004;98(8):777-781.

79. Pediatric Acute Lung Injury Consensus Conference Group. Pediatric acute respiratory distress syndrome: consensus recommendations from the Pediatric Acute Lung Injury Consensus Conference. Pediatr Crit Care Med 2015;16(5):428-439.

80. Mahle WT, Newburger JW, Matherne GP, Smith FC, Hoke TR, Koppel R, et al. Role of pulse oximetry in examining newborns for congenital heart disease: a scientific statement from the AHA and AAP. Pediatrics 2009;124(2):823-836.

81. Casavant DW, McManus ML, Parsons SK, Zurakowski D, Graham RJ. Trial of telemedicine for patients on home ventilator support: feasibility, confidence in clinical management and use in medical decision-making. J Telemed Telecare 2014;20(8):441-449.

82. Petterson MT, Begnoche VL, Graybeal JM. The effect of motion on pulse oximetry and its clinical significance. Anesth Analg 2007; 105(6 Suppl):S78-S84.

83. Barker SJ. "Motion-resistant" pulse oximetry: a comparison of new and old models. Anesth Analg 2002;95(4):967-972, table of contents.

84. Gehring H, Hornberger C, Matz H, Konecny E, Schmucker P. The effects of motion artifact and low perfusion on the performance of a new generation of pulse oximeters in volunteers undergoing hypoxemia. Respir Care 2002;47(1):48-60.

85. Hummler HD, Engelmann A, Pohlandt F, Högel J, Franz AR. Decreased accuracy of pulse oximetry measurements during low perfusion caused by sepsis: is the perfusion index of any value? Intensive Care Med 2006;32(9):1428-1431.

86. Bickler PE, Feiner JR, Severinghaus JW. Effects of skin pigmentation on pulse oximeter accuracy at low saturation. Anesthesiology 2005;102(4):715-719.

87. Zijlstra WG, Buursma A, Meeuwsen-van der Roest WP. Absorption spectra of human fetal and adult oxyhemoglobin, de-oxyhemoglobin, carboxyhemoglobin, and methemoglobin. Clin Chem 1991;37(9):1633-1638.

88. Akhtar J, Johnston BD, Krenzelok EP. Mind the gap. J Emerg Med 2007;33(2):131-132.

89. Arnold JH. Electrical impedance tomography: on the path to the Holy Grail. Crit Care Med 2004;32(3):894-895.

90. Hahn G, Sipinková I, Baisch F, Hellige G. Changes in the thoracic impedance distribution under different ventilatory conditions. Physiol Meas 1995;16(3 Suppl A):A161-A173.

91. Barber DC. Quantification in impedance imaging. Clin Phys Physiol Meas 1990;11(Suppl A):45-56.

92. Brown BH. Electrical impedance tomography (EIT): a review. J Med Eng Technol 2003;27(3):97-108.

93. Frerichs I. Electrical impedance tomography (EIT) in applications related to lung and ventilation: a review of experimental and clinical activities. Physiol Meas 2000;21(2):R1-R21. 
94. Leonhardt S, Lachmann B. Electrical impedance tomography: the holy grail of ventilation and perfusion monitoring? Intensive Care Med 2012;38(12):1917-1929.

95. Wolf GK, Gómez-Laberge C, Kheir JN, Zurakowski D, Walsh BK, Adler A, Arnold JH. Reversal of dependent lung collapse predicts response to lung recruitment in children with early acute lung injury. Pediatr Crit Care Med 2012;13(5):509-515.

96. Pulletz S, Adler A, Kott M, Elke G, Gawelczyk B, Schadler D, et al. Regional lung opening and closing pressures in patients with acute lung injury. J Crit Care 2012;27(3):323.e311-8.

97. Zhao Z, Steinmann D, Frerichs I, Guttmann J, Möller K. PEEP titration guided by ventilation homogeneity: a feasibility study using electrical impedance tomography. Crit Care 2010;14(1):R8.

98. Blankman P, Hasan D, van Mourik MS, Gommers D. Ventilation distribution measured with EIT at varying levels of pressure support and neurally adjusted ventilatory assist in patients with ALI. Intensive Care Med 2013;39(6):1057-1062.

99. Spooner AJ, Corley A, Sharpe NA, Barnett AG, Caruana LR, Hammond NE, Fraser JF. Head-of-bed elevation improves end-expiratory lung volumes in mechanically ventilated subjects: a prospective observational study. Respir Care 2014;59(10):1583-1589.
100. Miedema M, Frerichs I, de Jongh FH, van Veenendaal MB, van Kaam AH. Pneumothorax in a preterm infant monitored by electrical impedance tomography: a case report. Neonatology 2011;99(1):10-13.

101. Costa EL, Chaves CN, Gomes S, Beraldo MA, Volpe MS, Tucci MR, et al. Real-time detection of pneumothorax using electrical impedance tomography. Crit Care Med 2008;36(4):1230-1238.

102. Trepte CJ, Phillips CR, Solà J, Adler A, Haas SA, Rapin M, et al. Electrical impedance tomography (EIT) for quantification of pulmonary edema in acute lung injury. Crit Care 2016;20:18.

103. Ericsson E, Tesselaar E, Sjöberg F. Effect of electrode belt and body positions on regional pulmonary ventilation- and perfusionrelated impedance changes measured by electric impedance tomography. PLoS One 2016;11(6):e0155913.

104. Frerichs I, Pulletz S, Elke G, Reifferscheid F, Schadler D, Scholz J, Weiler N. Assessment of changes in distribution of lung perfusion by electrical impedance tomography. Respiration 2009;77(3):282-291.

105. Carlisle HR, Armstrong RK, Davis PG, Schibler A, Frerichs I, Tingay DG. Regional distribution of blood volume within the preterm infant thorax during synchronised mechanical ventilation. Intensive Care Med 2010;36(12):2101-2108.

\section{Discussion}

Cheifetz: In the near-infrared spectroscopy section of your talk, you acknowledge the data are limited as far as the usefulness of cerebral and renal near-infrared spectroscopy monitoring. But at least I can understand the physiology behind the rationale and technology to measure the oxygenation saturation of the brain and kidneys. However, you mentioned abdominal near-infrared spectroscopy. To me, that approach does not make any sense at all. For the brain and kidneys, there is a fixed and limited distance between the organ and the probe, but the bowels are always moving. So changes in the abdominal near-infrared spectroscopy value probably do not mean anything of clinical importance; fluctuations in the number may simply mean the intestines are moving. Do you have any data or thoughts to share? You opened up the gate on this one, even though I forewarned you that I would ask this question. Thoughts?

Smallwood: The primary reason I wanted to present it is because it's of interest in the ICU, and a fair number of folks are starting to use it. I completely agree that it's a really difficult organ or area of the body to probe accurately.
The limitation of near-infrared spectroscopy is that it's a near-surface regional $\mathrm{O}_{2}$ saturation; tissue and bone properties prevent the light from penetrating too far. Anything you're trying to measure has to be extremely close to the surface, near the probe to be reliable. Even when you're talking about probing the brain, the light doesn't penetrate the skull, so researchers are stuck with demonstrating correlations between surface tissue and cerebral tissue. Essentially, what you're hoping is that the tissue of your forehead is closely related to cerebral $\mathrm{O}_{2}$ saturation. The data are pointing in that direction. But as far as abdominal applications, I agree with you, Ira. Most of the data are in extremely small babies, in whom organs of interest (the kidneys, for example) are closer to the surface, and therefore the physical distance between the organ of interest and the actual sensor is fairly small. However, it's not clear to me that in patients as big as you or I or even in older pediatric patients, it would provide reliable measurements. It's probably not the best use of the technology in that case.

Stokes: I haven't followed this technology very closely, but in the early days, my impression was that they were using probes through the open fontanelle. Has the technology moved away from that?

Smallwood: Right. The technology has definitely evolved such that the probe placement is suggested to work in pre-term, infant, child, adolescent, and even adult patients. There is emerging evidence suggesting it's potentially useful, primarily for cerebral applications. But again, the closer you get to the organ of interest, the better. So if you're able to probe premature babies who have an incomplete closure of their cranial cavity, then you would probably have a much more reliable cerebral regional $\mathrm{O}_{2}$ saturation compared to a patient with a developed cranium.

* Branson: I spent about 10 years seemingly doing nothing but measuring EE in adults. I have 2 comments; one is $\dot{\mathrm{V}}_{\mathrm{O}_{2}}$ and $\dot{\mathrm{V}}_{\mathrm{CO}_{2}}$ are part of the equation, but $\dot{\mathrm{V}}_{\mathrm{O}_{2}}$ is predominately the factor that affects EE, and lots of people have suggested using $\dot{\mathrm{V}}_{\mathrm{O}_{2}}$ alone to determine $\mathrm{EE}$. But, of course, that's the more difficult value to measure. You're suggesting $\dot{\mathrm{V}}_{\mathrm{CO}_{2}}$ because it's almost always available, and therefore you can tolerate perhaps a greater error than $\dot{\mathrm{O}}_{\mathrm{O}_{2}}$ alone. My question is, at these low values, is that really something to do with the size of the patient, or is it simply in that group 
you're going to have more leaks around an uncuffed ETT, and it's a limitation of ability to collect all the expired volume more than it is something unique about a small baby?

Smallwood: It sounds like you're referring to the Kerklaan study ${ }^{1}$ that found that only in children $>15 \mathrm{~kg}$ was the $\dot{\mathrm{V}}_{\mathrm{CO}_{2}}$ EE estimate accurate. I think you bring up a reasonable point. In that study, the authors did their best to have reasonable exclusion criteria such that if you had excessive leak, $>10 \%$, then those patients would be excluded from analysis. However, that doesn't necessarily mean that there weren't any dynamic leaks during the study, because these children were spontaneously breathing and potentially moving around. As for your first comment regarding $\dot{\mathrm{V}}_{\mathrm{O}_{2}}$ and $\dot{\mathrm{V}}_{\mathrm{CO}_{2}}$, if you look at it, $\dot{\mathrm{V}}_{\mathrm{O}_{2}}$ is roughly 3 times as important in the Weir equation compared to $\dot{\mathrm{V}}_{\mathrm{CO}_{2}}$. But what you find is that the relationship between those 2 factors is linear, if RQ is held constant. If there aren't dynamic changes in RQ, and the RQ doesn't change a ton, then $\mathrm{V}_{\mathrm{CO}_{2}}$ and $\dot{\mathrm{V}}_{\mathrm{O}_{2}}$ will change linearly. It's also one of the screening/quality criteria for a standard indirect calorimetry test. If the measured RQ is out of whack, you assume your device isn't calibrated correctly, and you need to go back to the drawing board and redo your tests, which almost always reflects an error with the oxygen sensor. The potential advantages of using $\dot{\mathrm{V}}_{\mathrm{CO}_{2}}$ are that the technology is much more robust, it's less prone to error, it doesn't need to be zeroed nearly as often, and it can easily be applied continuously. It's a balancing act, but I think the $\dot{\mathrm{V}}_{\mathrm{CO}_{2}}$ method may work for the majority of patients, for technological reasons and, quite frankly, availability of the technology. The other area that's going to be really interesting to look at is longitudinal studies. An indirect calorimeter is both costly and somewhat unreliable because you constantly have to re-zero the machine every $12 \mathrm{~h}$ or so, and it is typically only applied for $30 \mathrm{~min}$ or so, precluding continuous measurement over many days. What's going to be interesting is if $\dot{\mathrm{V}}_{\mathrm{CO}_{2}}$ is indeed a reliable measure, we can then do all kinds of interesting studies looking at long periods of time in both nutrition and respiratory intervention clinical trials.

* Branson: This was done in the adult literature 20-25 years ago, looking at EE on a daily basis. I was intrigued because it's so complicated. For instance, you look at what the child is ordered to receive nutritionally and then go look at what they actually got, which had nothing to do with what was ordered, and it gets to be very difficult. The lucky thing for adults is they're so big you can be off by 10 $15 \%$, and in the long run it probably doesn't make any difference, but it probably is a huge difference in pediatrics from a nutritional standpoint.

Smallwood: Definitely. Children have a much, much smaller energy reserve, and I think that's probably why they're an interesting population for that kind of research and as such have a higher probability of positive effect from nutrition interventions, especially during critical illness.

Walsh: One of the things Craig and I have talked about a lot is the inaccuracy of flow measurements in the smaller kids. The inaccuracies tend to get wider (larger), if you will, and we wondered whether that contributes to some of the inaccuracies in $\dot{\mathrm{V}}_{\mathrm{O}_{2}}$ and $\dot{\mathrm{V}}_{\mathrm{CO}_{2}}$ in the smaller kids $(5-10 \mathrm{~kg})$. Leaving nutrition for now, what about other uses of these gas measurements? Specifically, your thoughts about using $\dot{\mathrm{V}}_{\mathrm{O}_{2}}$ or $\dot{\mathrm{V}}_{\mathrm{CO}_{2}}$ for cardiac output?

Smallwood: I know there are people interested in using $\dot{\mathrm{V}}_{\mathrm{CO}_{2}}$ to estimate cardiac output, especially in cardiac surgical populations. I don't have any personal experience in terms of research, but the idea has been around for some time. I think that the resurgence in interest has stemmed from the incorporation of the technology into the ventilators. I'm definitely excited to see what comes out of that, but I'm certainly a little skeptical, because this idea has been around for some time and cardiac output calculations require certain assumptions.

Cheifetz: We have done some work in our lab along those lines. From a pure physiology perspective, if minute ventilation is stable and $\dot{\mathrm{V}}_{\mathrm{CO}_{2}}$ is stable, at a point in time, $\dot{\mathrm{V}}_{\mathrm{CO}_{2}}$ must be proportional to pulmonary blood flow, which can be viewed as a surrogate for cardiac output. So, from a pure physiology perspective, they have to be aligned given my prior assumptions. The problem occurs in the clinical setting when $\dot{\mathrm{V}}_{\mathrm{CO}_{2}}$ and/or minute ventilation changes. Stated differently, all bets are off when the patient's respiratory status is changing at the same time his/her cardiac output (ie, pulmonary blood flow) is changing. This is obviously when physiology becomes complex. But, in a stable state, physiology says that $\dot{\mathrm{V}}_{\mathrm{CO}_{2}}$ must have a direct relationship to pulmonary blood flow.

Smallwood: Indeed. However, as more and more continuous data are being collected in the ICU, we may be able to chip away at the number of assumptions that are required and gain some accuracy. Time will tell.

\footnotetext{
* Richard D Branson MSc RRT FAARC, Deputy Editor, RESPIRATORY CARE.
}

\section{REFERENCE}

1. Kerklaan D, Augustus ME, Hulst JM, van Rosmalen J, Verbruggen SC, Joosten KF. Validation of ventilator-derived $\mathrm{V}_{\mathrm{CO}_{2}}$ measurements to determine energy expenditure in ventilated critically ill children. Clin Nutr 2017;36(2):452-457. 